\title{
ÖZGÜN ARAŞTIRMA
}

\section{HEMŞİRELERIN KISŞILIK ÖZELLIKKLERİ İLE ISS PERFORMANSLARI ARASINDAKİ İLIŞKIININ DEĞERLENDİRILMESI}

\author{
EVALUATION OF THE RELATIONSHIP BETWEEN PERSONALITY TRAITS AND JOB \\ PERFORMANCE OF NURSES
}

\author{
${ }^{1 *}$ Gülnur Gözel, ${ }^{2}$ Gümrah Duygu Atmaca, ${ }^{2}$ Gülgün Durat
}

ÖZET

ABSTRACT

${ }^{1}$ Psikiyatri Kliniği, Derince

Eğitim ve Araştırma Hastanesi, Kocaeli, Türkiye

${ }^{2}$ Sağlık Bilimleri Fakültesi, Sakarya Üniversitesi, Sakarya, Türkiye

Received: 14.01.2017

Accepted: 24.01.2017

Sorumlu yazar

Gülnur Gözel

Psikiyatri Kliniği, Derince Eğitim ve Araştırma Hastanesi, Kocaeli, Türkiye

e- mail: gulnurgzl@hotmail.com

Hemşirelik mesleği, toplumun sağlığının korunması, sürdürülmesi ve hastalık durumunda iyileştirme gibi görevler yüklenmiştir. Hastanelerde iş gücünün büyük bir kısmını hemşireler oluşturmaktadir.

Kişilik kavramı, birçok şekilde açıklanmıştır. Bir açıklamada bireyi diğerlerinden ayıran nispeten kalıcı özellikler ve eğilimler olarak tanımlanırken bir başkasında bireyin genel olarak sergilediği davranış, düşünce ve duygu eğilimleri olarak tanımlanmıştır. Aynı olaylar karşısında farklı çözümler geliştirmenin nedenlerinden birinin bireylerin sahip olduğu kişilik özellikleri olduğu söylenebilir ${ }^{1}$.

Kişiliği açıklamaya yönelik birçok yaklaşım bulunmakta olup, boyutsal olarak ele alan ilk kişi Eysenck'tir. Eysenck kişilik teorisi, ilk ortaya koyulduğunda nörotisizm-stabilite ve dışadönüklük-içe dönüklük boyutlarını içerirken, daha sonra psikotisizm boyutu da eklenmiştir² D1şa dönüklük, sosyalliği ve dürtüselliği temsil ederken nörotisizm boyutu kaygıll, depresif, gergin, çekingen, mantık dişı davranışlar göstermeye yatkınlık, aşırı duygusal ve düşük özgüveni temsil etmektedir. Psikotisizm boyutu ise soğuk, mesafeli, saldırgan, güvensiz, anti sosyal davranışlar, empati kuramama, suçluluk ve diğer insanlara karşı duyarsızlık gibi daha çok sıradışı kişilik özelliklerini ifade etmektedir ${ }^{3-5}$.

Çalışanların kişilik özelliklerini bilmek, mesleklerinde sergilemiş oldukları performansı tespit etmeye yardimc Hemşirelerin iş performansları, hasta bakım kalitesinin önemli bir göstergesi olarak değerlendirilmektedir ${ }^{6}$. Kurum, performansını artırmak için, çalışanların duygu ve düşüncelerini, tutum ve davranışlarını, istek ve ihtiyaçlarını, 
bunlara etki eden kurum içi ve kurum dışı faktörleri dikkate almalıdır? . Artmış iş performansı, kurumlar için olduğu kadar çalışanlar içinde önemlidir. Yapılan işte başarılı olmak birey için daha iyi bir kariyeri, sosyal prestiji ve iş doyumunu beraberinde getirir ${ }^{8}$. Bu konuda yapılan çalışmalar kişilik özelliklerinin; iş performansı, kariyer, yönetimin stratejileri ve liderlik gibi değişkenlerle ilişkili olduğunu göstermiştir?

Ülkemizdeki sağlık hizmetleri kalite düzeyi ile ilgili yapılacak çalışmalar, hasta bakımını ve sunulan hizmetin kalitesini artıracaktır. Bu düşünceden yola çıkarak bu araştırmada, hastanelerde iş gücünün önemli bir parçasını oluşturan hemşirelerin kişilik özelliklerinin bireysel performans standartlarına etkisini incelemek amaçlanmıştır.

\section{Yöntem}

Tanımlayıcı tipte tasarlanan araştırmanın örneklemini çalışmaya katılmayı kabul eden 171 hemşire oluşturmuştur. Çalışmadaki veriler hazırlanan soru formlarının 15 Mart-16 Nisan 2016 tarihleri arasında çevrimiçi olarak katılımcılara gönderilmesiyle toplanmıştır. Araştırmada veriler, Görüşme Formu, Eysenck Kişilik Anketi-Gözden Geçirilmiş Kısaltılmış Formu(EKA-GGK) ve Hemşirelik İş Yaşamı Kalitesi Ölçeği kullanılarak elde edilmiştir.

Görüşme formu; araştırmacı tarafından hazırlanmış, hemşirelerin sosyodemografik özellikleri ile çalışma durumuna ait bilgileri içeren toplam 9 sorudan oluşmaktadır. EKA-GGK, Francis ve arkadaşları (1992) tarafından oluşturulmuş 24 maddelik öz bildirim ölçeğidir ${ }^{10}$. Bu form, dişa dönüklük, nörotizm, psikotizm ve yalan söyleme olmak üzere, dört alt boyuttan oluşmaktadır. Kişiliği; dışa dönüklük, nörotizm ve psikotizm boyutlarında değerlendirmektedir. Yalan söyleme alt boyutuyla formun uygulanması esnasındaki yanlılığı engellemek ve geçerliliği ile ilgili kontrol amaçlanmaktadır. Her bir boyutta toplam 6 madde yer almaktadır ve her bir boyuttan alınabilecek en yüksek puan, altıdır. Formda, 3, 5, 7, 10, 15, 16, 17, 19, 20, 22. maddelerde ters puanlama yapılmaktadır. Ölçek bir öz bildirim ölçeği olup alt boyutlarının kesme noktaları hesaplanmamıştır, sadece karşılaştırmalı çalışmalarda kullanılabilir.

Karancı ve diğ., 24 maddelik EKA-GGK'yi, 756 üniversite öğrencisine uygulayarak, Türkiye'deki geçerlik ve güvenilirlik çalışmasını yapmışlardır. Ölçeğin iç tutarlığı için Kuder-Richardson 20 yöntemi kullanılmıştır. Kuder Richardson alfa değerleri; dişa dönüklük, psikotizm ve yalan boyutları için sırasıyla. $0.78,0.65,0.42$ ve 0.64 olarak saptanmıștır. Ölçeğin test tekrar test güvenilirliği için Pearson korelasyon katsayısı hesaplanmış ve nörotizm, dışa dönüklük, psikotizm ve yalan alt boyutlarında sırasıyla; 0.82, 0.84, 0.69, $0.69(\mathrm{p}<0.001)$ olarak hesaplanmıştır. Ayrıca Karancı vd. ölçeğin yapı geçerliğinin de üniversite öğrencileri örnekleminde oldukça iyi olduğunu belirtmişlerdir ${ }^{5}$.

Hemşirelik İş Yaşamı Kalitesi Ölçeği (HİYKÖ), hemşirelerin iş yaşamı kalitesini tespit etmek amacı ile Brooks tarafından 2001 yılında geliştirilmiş, geçerlik ve güvenilirliği Şirin tarafından 2011 yılında yapılmıştır ${ }^{11,12} .35$ maddelik HIYKÖ’nin Türkçe formu, iş/çalışma ortamı, yöneticilerle ilişkiler, iş koşulları, iş algısı ve destek hizmetler olmak üzere toplam 5 alt boyuttan oluşmaktadır. Ölçek 5'li likert tipi şeklindedir ve her bir soru için hemşirelerden $\quad 1=$ Kesinlikle Katılmıyorum, 2=Katılmıyorum, $\quad 3=$ Kararsızım, $\quad 4=$ Katılıyorum, 5=Kesinlikle Katılıyorum seçeneklerinden uygun buldukları ifadeyi işaretlemeleri istenmektedir. Ölçeğin alt boyutlarında yer alan sorulara göre dağılımları şu şekildedir: 1. İş/çalışma ortamı: Hemşireler için olumlu çalışma ortamını tanımlayan bu faktör grubu 4, 12, 19, 26, 29, 30, 31, 32 ve 33. maddeler olmak üzere 9 maddeden oluşmaktadır. 2. Yöneticiler ile ilişkiler: Hemşireliğin temeli olan iletişim sürecinde hemşirelerin yöneticileri ile ilişkilerini tanımlayan bu faktör grubu 7, 9, 20, 24 ve 28. maddeler olmak üzere 5 maddeden oluşmaktadır. 3 . İş koşulları: Hemşirelerin iş dışı zamanlarını da etkileyen ve hemşirelik mesleği ile ilgili olan etkenleri tanımlayan bu faktör grubu 3, 5, 10, 11, 14, 15, 16, 18,22 ve 23 . maddeler olmak üzere 10 maddeden oluşmaktadır. 4. İş Algısı: Hemşirelerin, hemşirelik mesleği ve iş ortamı ile ilgili görüşlerini tanımlayan bu faktör grubu $2,6,13,17,25,27$ ve 34. maddeler olmak üzere 7 maddeden oluşmaktadır. 5. Destek hizmetler: Hemşirelik hizmetlerinin, ekipman yeterliliği, malzemeye ulaşabilirlik gibi tıbbi-idari-mali destek hizmetler tarafından desteklenip desteklenmediğini tanımlayan bu faktör grubu 1, 8, 21 ve 35. maddeler olmak üzere 4 maddeden oluşmaktadır. Şirin'in çalışmasında ölçeğin Cronbach's Alpha katsayısı, 0.89 olarak bulunmuştur, ölçeğin alt boyutlarının Cronbach's Alpha katsayıları ise 0.62-0.81 arasındadır. Ölçeğin 3,11, 16 ve 20. maddeleri ters puanlanmakta ve ölçekten alınabilecek en düşük puan 35 , en yüksek puan ise 175 'dir. HIYKKÖ'den alınan toplam puanın artması hemşirelerin iş yaşamı kalitesinin yüksek olduğunu, azalması ise hemșirelerin iş yaşamı kalitesinin düșük olduğunu göstermektedir ${ }^{12}$.

\section{Verilerin Analizi ve Değerlendirilmesi}

Veriler bilgisayar ortamına aktarıldıktan sonra SPSS 21.0 (SPSS, Chicago, IL., USA) paket programı ile analizleri yapılmıştır. Tanımlayıcı istatistikler sayı, yüzde, ortalama, standart sapma, en küçük ve en büyük olarak verilmiştir. Sürekli verilerin normal dağılıma uygunluğu KolmogorovSmirnov Testi ile belirlendikten sonra normal dağılıma uymayan verilerin karşılaştırılmasında Mann-Whitney U ve Kruskal wallis testi, değişkenler arası ilişkiyi göstermek için ise Pearson korelasyon testi kullanılmıștır. Korelasyon katsayıs1 0,05-0,40 aras1 zayıf, 0,41-0,70 aras1 orta derecede, $>0,71$ güçlü ilişki olarak değerlendirilmiştir. İstatistiksel anlamlılık değeri $p<0,05$ olarak kabul edilmiştir.

\section{Bulgular}

Araştırmanın örneklemi oluşturan hemşirelerin yaş ortalaması $30,37 \pm \quad 6,33$ olup, \%11,7'sini erkekler, \%88,3'ünü kadınlar oluşturmaktadır (Çizelge 1).

Hemşirelerin \%76'sı lisans ve üstü mezunu iken \% 9,4'ü sağllk meslek lisesinden mezun olmuştur. Hemşirelerin $\% 16,3$ 'ü 15 yıldan daha uzun süredir çalışmakta, \%50,3'ü ayda 6 ve daha fazla nöbet tutmaktadır. Katılımcıların $\% 65,5$ 'i gece/gündüz vardiya şeklinde çalışırken \%7'si 
sadece gece nöbeti tutmaktadır. Hemşirelerin \%63,7'si fazla mesaili çalışmaktadır.

Çizelge 1. Katılımcıların sosyodemografik özellikleri.

\begin{tabular}{|c|c|c|}
\hline Sosyodemografik Özellikler & Sayı $(n=171)$ & Yüzde \\
\hline \multicolumn{3}{|l|}{ Cinsiyet } \\
\hline Erkek & 20 & 11,7 \\
\hline Kadın & 151 & 88,3 \\
\hline \multicolumn{3}{|l|}{ Eğitim Düzeyi } \\
\hline Sağlık Meslek Lisesi & 16 & 9,4 \\
\hline Önlisans & 25 & 14,6 \\
\hline Lisans & 97 & 56,7 \\
\hline Yüksek Lisans ve Sonrası & 33 & 19,3 \\
\hline \multicolumn{3}{|l|}{ Çalışma Yılı } \\
\hline $0-4,9$ yil & 71 & 41,5 \\
\hline $5-9,9$ yll & 49 & 28,7 \\
\hline $10-14,9$ yıl & 23 & 13,5 \\
\hline 15 yıl ve üzeri & 28 & 16,3 \\
\hline \multicolumn{3}{|l|}{ Çalışma Şekli } \\
\hline Gece/ Gündüz Vardiya & 112 & 65,5 \\
\hline Sadece Gece Nöbeti & 12 & 7 \\
\hline Sadece Gündüz & 47 & 27,5 \\
\hline \multicolumn{3}{|l|}{ Aylık Tutulan Nöbet Sayısı } \\
\hline $1-5$ aras 1 & 41 & 24 \\
\hline 6 ve üzeri & 86 & 50,3 \\
\hline Nöbet tutmayan & 44 & 25,7 \\
\hline \multicolumn{3}{|l|}{ Haftalık Çalışma Saati } \\
\hline 40 saat & 62 & 36,3 \\
\hline 40 saat üzeri & 109 & 63,7 \\
\hline
\end{tabular}

Katılımciların EKA-GGK genel toplam puan ortalamas1 $12,41 \pm 2,61$ 'tür $(n=171)$. Katılımciların "yalan" alt boyut puan ortalamas1 4,19 $\pm 1,32$; "psikotisizm" alt boyut puan ortalamas1 1,22 $\pm 1,03$; "nörotisizm" alt boyut puan ortalaması $3,16 \pm 1,85$ ve "dıșa dönük" alt boyut puan ortalaması 3,83 $\pm 1,92$ olarak bulunmuştur. EKA-GGK ölçeğinden katılımcılar en düşük 5, en yüksek 19 puan almıştır. EKA-GGK alt boyutları cinsiyete $(p=0,55)$, çalışma şekline $(p=0,49)$, aylık nöbet sayısına $(p=0,14)$ ve eğitim durumuna $(p=0,08)$ göre karşılaştırıldığında istatistiksel olarak anlamlı fark bulunmamıştır. Buna karşın haftalık çalışma saatine göre karşılaştırıldığında ise psikotisizm alt ölçeğinde istatistiksel olarak anlamlı fark bulunmuştur $(\mathrm{p}=0,04)$. 40 saat ve üzeri çalışanlarda $(\mathrm{n}=109)$ psikotisizm alt boyut puan ortalaması $1,33 \pm 1,04$ iken, 40 saat çalışanlarda $(n=62) 1,03 \pm 1,00$ 'tür.

Hemşirelerin çalıştıkları süreye göre EKA_GGK' nın alt ölçekleri karşılaştırıldığında yalan ve nörotisizm alt ölçeklerinde gruplara göre puan ortalamalarında istatistiksel olarak anlamlı farklılık bulunmuştur $(p=0,005$ ve $p=0,001)$ (Çizelge 2). $\mathrm{Bu}$ farklılığın hangi iki alt gruptan kaynakladığını bulmak için yapılan Bonferroni düzeltmeli Mann Whitney U testi yapıldığında, yalan alt ölçeğindeki farklılığın 0-4,9 y1l ve 15 y1l üstü çalışanlardan $(\mathrm{p}<0,001)$, nörotisizm alt ölçeğindeki farklılığın ise 0-4,9 yıl ile 10-14,9 yıl arası çalışanlardan kaynaklandığı tespit edilmiştir (p $<0,001)$.

Çizelge 2. EKA-GGK alt ölçek puanlarının çalıșma yıllarına göre karşılaştırılması.

\begin{tabular}{|c|c|c|c|c|c|}
\hline $\begin{array}{c}\text { EKA-GGK } \\
\text { Alt } \\
\text { Boyutları }\end{array}$ & $\begin{array}{l}\text { Çalışma } \\
\text { Yılı }\end{array}$ & Sayı & Ortalama & $\begin{array}{c}\text { Standart } \\
\text { Sapma }\end{array}$ & $p^{*}$ \\
\hline \multirow{5}{*}{$\begin{array}{c}\text { Dişa } \\
\text { Dönüklükk }\end{array}$} & $0-4,9$ & 71 & 3,6338 & 1,93641 & \multirow{5}{*}{0,52} \\
\hline & $5-9,9$ & 49 & 3,9796 & 1,97368 & \\
\hline & $10-14,9$ & 23 & 4,2609 & 1,60163 & \\
\hline & $\begin{array}{l}15 \text { ve } \\
\text { üzeri }\end{array}$ & 28 & 3,7143 & 2,08801 & \\
\hline & $0-4,9$ & 71 & 3,831 & 1,19506 & \\
\hline \multirow{3}{*}{ Yalan } & $5-9,9$ & 49 & 4,3673 & 1,33376 & \multirow{3}{*}{0,005} \\
\hline & $10-14,9$ & 23 & 4,2174 & 1,56544 & \\
\hline & $\begin{array}{l}15 \text { ve } \\
\text { üzeri }\end{array}$ & 28 & 4,8214 & 1,15642 & \\
\hline \multirow{5}{*}{ Nörotisizm } & $0-4,9$ & 71 & 3,7324 & 1,74812 & \multirow{4}{*}{0,001} \\
\hline & $5-9,9$ & 49 & 3,1633 & 2,03457 & \\
\hline & $10-14,9$ & 23 & 2,1739 & 1,52709 & \\
\hline & $\begin{array}{l}15 \text { ve } \\
\text { üzeri }\end{array}$ & 28 & 2,5357 & 1,57485 & \\
\hline & $0-4,9$ & 71 & 1,1831 & 1,04622 & \multirow{4}{*}{0,59} \\
\hline \multirow{3}{*}{ Psikotisizm } & $5-9,9$ & 49 & 1,1429 & ,93541 & \\
\hline & $10-14,9$ & 23 & 1,2174 & 1,12640 & \\
\hline & $\begin{array}{l}15 \mathrm{ve} \\
\text { üzzeri }\end{array}$ & 28 & 1,4643 & 1,13797 & \\
\hline
\end{tabular}

*Kruskal Wallis testi

Katılımcıların Hemşirelik İş Yaşamı Kalitesi Ölçeği toplam puan ortalamas1 $94,67 \pm 14,66^{\circ}$ dır $(n=171)$. HIYKÖ'den en düşük 64, en yüksek 135 puan alınmıştır. Katılımcıların "iş/çalışma ortamı" alt boyut puan ortalaması 21,02 $\pm 5,96$; "yöneticiler ile ilişkiler" alt boyut puan ortalaması $14,31 \pm 3,18$; “iş koşulları" alt boyut puan ortalaması $26,83 \pm 5,59$; "iş algısı" alt boyut puan ortalaması $21,02 \pm 5,96$ ve "destek hizmetler" alt boyut puan ortalamas 1 $11,21 \pm 3,56$ olarak bulunmuştur. 
HIYKÖ alt boyutları cinsiyet, haftalık çalışma saati, eğitim durumu ve çalışma yllına göre karşılaştıııldığında istatistiksel olarak anlamlı farklılık bulunmamıştır $(\mathrm{p}>0,05)$. HIYKÖ alt boyutları aylık tutulan nöbet sayısına karşılaştırıldığında iş/çalışma ortamı alt boyutunda $(\mathrm{p}=0,03)$, çalışma şekline göre karşılaştırıldığında ise yöneticilerle ilişkiler alt boyutunda istatistiksel olarak anlamlı farklılık bulunmuştur.

HİYKÖ'nün iş/çalışma ortamı alt boyutu, aylık tutulan nöbet sayılarına göre karşılaştırıldığında bulunan istatistiksel anlamlılı̆ğı hangi iki alt gruptan kaynakladığını bulmak için yapılan Bonferroni düzeltmeli Mann Whitney $U$ testi sonucunda farkın nöbet tutmayanlar ile 1-5 arasında nöbet tutanlardan kaynakladığı bulunmuştur $(\mathrm{p}=0,004)$ (Çizelge $3)$.

Çizelge 3. Aylık tutulan nöbet sayılarına göre iş-çalışma ortamı alt boyutunun karşılaştırılması.

\begin{tabular}{c|lccc}
\hline $\begin{array}{c}\text { HiYKÖ Alt } \\
\text { Ölçeği }\end{array}$ & $\begin{array}{c}\text { Aylık Tutulan } \\
\text { Nöbet Sayısı }\end{array}$ & Sayı (n=171) & $\begin{array}{c}\text { Ortalama- } \\
\text { Standart } \\
\text { Sapma }\end{array}$ & $\mathbf{p}^{*}$ \\
\hline $\begin{array}{c}\text { İş/ } \\
\text { Çalşma } \\
\text { Ortamı }\end{array}$ & $1-5$ arası & 41 & $20,51 \pm 6,38$ & \\
& 6 ve üzeri & 86 & $20,67 \pm 5,42$ & 0,03 \\
\hline
\end{tabular}

* Kruskal Wallis Testi

HIYYKÖ’nün yöneticilerle ilișkiler alt boyutu çalıșma șekline göre karşılaş̧tırıldığında bulunan istatistiksel anlamlılı̆̆ın hangi iki alt gruptan kaynakladığını bulmak için yapılan Bonferroni düzeltmeli Mann Whitney $\mathrm{U}$ testi sonucunda sadece gece ve sadece gündüz çalışanlardan kaynaklandığ bulunmuştur.( $p<=0,001)$ (Çizelge 4).

Çizelge 4. Çalışma şekline göre yöneticilerle ilişkiler alt boyutunun karşılaştırılması.

\begin{tabular}{c|lccc}
\hline $\begin{array}{c}\text { HiYKÖ Alt } \\
\text { Ölçeği }\end{array}$ & \multicolumn{1}{|c}{$\begin{array}{c}\text { Çalışma } \\
\text { Şekli }\end{array}$} & $\begin{array}{c}\text { Sayı } \\
(\mathbf{n = 1 7 1})\end{array}$ & $\begin{array}{c}\text { Ortalama- } \\
\text { Standart Sapma }\end{array}$ & $\mathbf{p}^{*}$ \\
\hline \multirow{2}{*}{$\begin{array}{c}\text { Yöneticilerle } \\
\text { ilişkiler }\end{array}$} & $\begin{array}{l}\text { Gece/gündüz } \\
\text { vardiya }\end{array}$ & 112 & $14,11 \pm 3,10$ & \\
& $\begin{array}{l}\text { Sadece gece } \\
\text { Sadece } \\
\text { gündüz }\end{array}$ & 12 & $12,58 \pm 2,77$ & 0,02 \\
\hline
\end{tabular}

\footnotetext{
* Kruskal Wallis Testi
}

Yapılan istatistik değerlendirmesi sonucunda hemşirelerin, iş/çalışma ortamı ve nörotisizm alt boyutları arasında anlamlı negatif yönde ve zayıf korelasyon $(\mathrm{p}=0,05, \mathrm{r}=$ $0,145)$; iş koşulları ile nörotisizm alt boyutları arasında anlamlı negatif yönde ve zayıf korelasyon $(\mathrm{p}=0,01, \mathrm{r}=$ $0,184)$; destek hizmetler ile psikotisizm alt boyutları arasında anlamlı negatif yönde ve zayıf korelasyon $(\mathrm{p}=0,01$, $r=-0,187$ ) saptanmıştır ( Çizelge 5).

Çizelge 5. EKA-GGK alt boyutlarının HIYKO alt boyutları ile olan ilişkisinin korelasyon katsayıları (r)*

\begin{tabular}{l|cccc}
\hline & Nörotisizm & Yalan & Psikotisizm & Dışa Dönüklük \\
\hline $\begin{array}{l}\text { İş/Çalışma } \\
\text { Ortamı }\end{array}$ & $\mathbf{- 0 , 1 4 5}$ & 0,072 & $-0,129$ & $-0,034$ \\
$\begin{array}{l}\text { Yöneticilerle } \\
\text { İlişkiler }\end{array}$ & $-0,043$ & 0,069 & $-0,107$ & 0,036 \\
$\begin{array}{l}\text { İş Koşulları } \\
\text { İş Algısı }\end{array}$ & $-\mathbf{0 , 1 8 4}$ & 0,050 & 0,053 & 0,022 \\
$\begin{array}{l}\text { Destek } \\
\text { Hizmetler }\end{array}$ & $-0,145$ & 0,072 & $-0,129$ & $-0,034$ \\
\hline
\end{tabular}

*Pearson Korelasyon Testi

\section{Tartışma}

$\mathrm{Bu}$ çalışma örneklemiyle kısıtlıdır. Hemşirelik mesleğinin daha çok kadı tarafindan icra edilmesi nedeniyle katılımcıların cinsiyet dağılımı eşitlenememiş ve $\% 88,3$ 'ü kadınlardan oluşmuştur.

EKA-GGK alt boyutları haftalık çalı̧̧ma saatlerine göre karşılaştırıldığında psikotisizm alt boyutunda istatistiksel olarak anlaml fark bulunmuştur $(\mathrm{p}=0,04)$. Bu alt boyutta bulduğumuz farklılı̆ı̆n nedeninin, Bohle ve diğ. çalışmasında bahsettiği gibi, fazla ve düzensiz çalışma saatleri nedeniyle yaşadıkları uyku bozuklukları, iş yüklerinin ağır ve yorucu olması nedeniyle duyarsızlaşma, saldırganlaşma gibi geliştirdikleri kişilik özellikleri olabileceği değerlendirilmektedir ${ }^{13}$.

Çalışma yılı EKA-GGK yalan alt boyutunun 15 yıldan fazla çalışanlarda yüksek olmasının nedeninin, mesleki tecrübelerinin fazla olması nedeniyle sorulara doğru cevap verebilmek ve hata yapmamak için artan kaygı düzeyleri nedeniyle verdikleri yanlış cevaplardan kaynaklandığı düşünülmektedir.

Nörotisizm alt ölçeği puan ortalamasının 5 yıldan az çalışanlarda yüksek çıkması, mesleğe yeni başlamaları nedeniyle tecrübelerinin az olmasından kaynaklanan özgüven düşüklüğü, artmış kaygı düzeyi ve çekingen kişilik özellikleri sergilemeleriyle açıklanabilir. Shevlin ve diğ. çalışmasında kadınlarda, başka benzer çalışmalar ise ergen ve genç yetişkin bireylerde nörotizmin fazla olduğunu belirtmektedir ${ }^{14}$. Çalışmamızın örnekleminin çoğunluğunun kadınlardan oluşması ve mesleğe yeni başlayan genç hemşireler olmaları nedeniyle nörotisizm puanlarının yüksek olması literatürle uyumlu bulunmuştur.

$\mathrm{Bu}$ çalışma sonucuna göre hemşirelerin iş yaşamı kalitesinin puan ortalaması $94,67 \pm 14,66$ olup orta düzeyde olduğu 
sonucu çıkarılabilir. Bu alanda yapılan diğer çalışmalarda da hemşirelerin iș yaşamı kalitesi orta seviyede bulunmuştur $^{12,15,16}$. Literatürde çalışmamıza benzer şekilde vardiya sistemi ile çalışan hemşirelerin iş yaşamı kalitesi düşükken; sadece gündüz vardiyasında çalışan hemşirelerin iş yaşamı kalitesi daha yüksek bulunmuştur ${ }^{17}$.

Hemşirelerin iş yaşamı kalitesi alt ölçeklerinden en düşük puan ortalamasının, tıbbi-idari-mali destek hizmetler tarafından desteklenip desteklenmediğini tanımlayan "destek hizmetler" alt boyutundan, en yüksek puan ortalamasının ise "iş koşulları" alt boyutundan alındığ 1 görülmektedir.

Çalışanların güvenli bir çevrede çalışmaları, iş yerinde bireysel zararlara karşı (fiziksel, duygusal, sözel) kendilerini güvende hissetmeleri, hemşirelik prosedür ve talimatları gibi işlerini kolaylaştıran olumlu faktörlerin çalışma ortamında bulunmasını ifade eden iş/çalışma ortamı alt boyutu puan ortalamas1, nöbet tutmayan hemşirelerde, nöbet tutan hemşirelere göre yüksek bulunmuştur. Gibson yapmış olduğu bir araştırmada güvenin verimliliği artırdığını, çalışanın moralini, takım performansını ve örgütsel performansı yükselttiğini belirtmiştir ${ }^{18}$. Yapılan bir çalışmada da sağlık çalışanlarının çalışma ortamlarını kaliteli bulmadıkları ve bu durumun çalışma yaşamlarını olumsuz olarak etkilediği görülmüştür ${ }^{19}$. Nöbet tutan hemşireler geceleri çalıştıkları için şiddetle daha fazla karşılaşma olasılıklarının olduğunu düşünüyor olabilirler. Ayrıca gece çalışmanın getirdiği uyku problemleri, düzensiz yaşam biçimi gibi sorunlar, hemşirelerin iş/çalışma ortamlarına bakış açısını negatif yönde etkileyebilmektedir.

HIYKÖ'nün yöneticilerle ilişkiler alt boyutu ile katılımcıların çalışma şekli karşılaştırıldığında sadece gündüz çalışanlarda yöneticilerle ilişkilerin daha iyi olduğu bulunmuştur. Gündüz çalışmalarına olanak sağlayan amirlere karşı olumlu bakış açılarının olması, mesai saatlerinde yöneticilere ulaşmanın daha kolay olması gibi nedenlerden dolayı yöneticilerle iletişimin iyi kurulabilmesi, gündüz çalışanların nöbet usulü çalışanlara göre daha yüksek puan almalarını açıklamaktadır. Selvi ve diğ. tarafından yapılmış olan bir çalışmada vardiyalı sistemde gece çalışan bireylerde anksiyete ve depresyon bozukluğunun yaygın olduğunu saptamıştır. Buna bağlı olarak gelişen sosyal uyumsuzluk ve bozulmuş kişiler arası ilişkiler bireyin sağlıklı iletişim kurmasını engellemektedir ${ }^{20}$.

İş/çalışma ortamı ve nörotisizm alt boyutları arasında istatistiksel olarak anlamlı negatif yönde ve zayıf korelasyon bulunmuştur. Çalışma ortamında kişi-çevre uyumu önemlidir. Uygun çevre, iş doyumunu arttırmakta dolayısıyla iş performansı olumlu yönde etkilenmektedir ${ }^{19}$. Kılıç ve Keklik'in yaptığı çalışmada, sağlık çalışanları için iş yaşamı kalitesinin arttırılması hususunda önemli faktörlerden birinin çalışma ortamının kalitesinin yükseltilmesi olduğu görülmüştür ${ }^{21}$. Çalışma ortamını olumlu hale getiren çevre güvenliği, kişisel güvenlik gibi etkenler arttıkça, hemşirelerde tedirgin olma, çekingen olma, olaylar karşısında aşırı duygusal davranma durumu azalmaktadır.

İş ve özel hayat dengesinin kurulmasını değerlendiren iş koşulları ile nörotisizm alt boyutu arasında bulunan anlamlı, negatif yönlü ve zayıf korelasyon, hemşirelerin duygusal, depresif, gergin, çekingen kişilik özelliklerinin iş koşullarını olumsuz anlamda etkilemesinden kaynaklanabilir. Aynı zamanda bu durumun tam tersi olarak olumsuz iş koşulları da kişilik özelliklerini etkiliyor olabilir. Ayrıca yapılan bir çalışmada vardiyalı çalışma sistemiyle çalışanların kendilerini dışlanmış hissettiklerinden dolayı sosyal ve aile içi rollerini yerine getirmekte güçlük yaşadıkları belirtilmiştir. Yaşadıkları bu olumsuz duyguların bireyin anksiyetesinin artmasına, benlik saygısının da azalmasına yol açtığı gözlenmiştir ${ }^{22}$.

Destek hizmetler ile psikotisizm alt boyutu arasında istatistiksel olarak anlamlı negatif yönde zayıf ilişki bulunmuştur. Çalışmamıza benzer şekilde Demir de farklı hastane gruplarında yaptığı bir çalışmada, hemşirelerin hastanelerinde yeterli malzeme bulunmamasının kendilerini negatif yönde etkilediğini belirtmiştir ${ }^{23}$. Destek hizmetlerdeki yetersizliğin çalışanları saldırgan, güvensiz ya da duyarlılıktan yoksun hale getirebileceği düşünülebilir.

\section{Sonuç Ve Öneriler}

Yapılan bu araştırma sonucunda kişilik özelliklerinin iş performansıyla etkileşim halinde olduğu ortaya konulmuştur. Bizim çalışmamız da Yelboğa ve Barrick tarafından yapılan kişilik özellikleri ve iş performansı ilişkisini açıklamaya çalışan araştırmalara benzer sonuçlar vermektedir ${ }^{9,24}$.

Fiziksel koşulların olumsuzluğu, yetersiz hemşire sayısı, vardiya sistemi, uzun çalışma saatleri, iş yükünün ağır ve yorucu olması gibi sorunları iyileştirmeye yönelik uygulama ve politikalar geliştirilmelidir.

Hemşirelerin ruh sağlı̆̆ını korumak ve sürdürmek için, problem çözme becerileri ile mesleki ve kişisel benlik saygısının geliştirilmesine yardımcı olan konsültasyon liyezon psikiyatri birimleri kurularak sağlık çalışanlarına psikososyal destek verilmeli, iş stresiyle baş edebilmelerinde ya da ekip içi çatışmaların çözümlenmesinde yol gösterilmelidir.

Mesleğe yeni başlayan hemşirelere oryantasyon ve ekip içi kaliteli iletişim eğitimleri, çalışma ortamında izole olma sorunları yaşayan veya öfke ve stres yönetimi zayıf olan hemşirelere iş performansını ve kişinin kendini tanımasını sağlayan atılganlık becerileri eğitimleri verilmelidir.

\section{Kaynaklar}

1. Erkuş A, Tabak A. Beş faktör kişilik özelliklerinin çalışanların çatışma yönetim tarzlarına etkisi: savunma sanayiinde bir arastırma. Atatürk Üniversitesi İktisadi ve İdari Bilimler Dergisi. 2009; 23(2): 213-242.

2. Lewis CA, Francis LJ, Shevlin M. Confirmatory factor analysis of the French translation of the abbreviated form of the Revised Eysenck Personality Questionnaire (EPQR-A). European J Psychol Assess. 2002; 18: 79-85.

3. Eysenck HJ, Eysenck MW. Personality and Individual Differences: A Natural Science Approach. New York, 1985

4. Eysenck HJ, Eysenck SB. Manual of the Eysenck Personality Questionnaire (adult and junior). Hodder\& Stoughton, London, 1975.

5. Karancı N, Dirik G, Yorulmaz O. Eysenck Kișilik Anketi Gözden Geçirilmi Kısaltılmış Formu'nun (EKA-GGK) Türkiye'de Geçerlik ve Güvenilirlik çalışması. Türk Psikiyatri Dergisi. 2007; 18(3).

6. Ma CC, Samuels ME, Alexander JW. (2003). Factors that influence nurses' job satisfaction. JONA. 2003; 3(5): 293-299.

7. Doğanlı B, Demirci Ç. Sağlık kuruluşu çalışanlarının (hemşire) motivasyonlarını belirleyici faktörler üzerine bir araştırma. Yönetim ve Ekonomi. 2014; 21(1): 47-60.

8. Sonnentag S,Frese M. Performance Concepts and Performance Theory. In S. Sonnentag (Ed.) Psychological Management of Individual Performance. John Wiley \& Sons, Ltd, 2002; s. 4-25. 


\section{G. GÖZEL ve diğ.}

9. Yelboğa A. Kişilik özellikleri ve iş performansı arasındaki ilişkinin incelenmesi. İş, Güç Endüstri İlişkileri ve İnsan Kaynakları Dergisi. 2006; 8(2): 196-211.

10. Francis LJ, Brown LB, Philipchalk R. (1992). The development of an abbreviated form of the revised Eysenck Personality Questionnaire (EPQR-A): its use among students in England, Canada, the U. S. A. And Australia. Personality and Individual Difference. 1992; 13 (4): 443-449.

11. Brooks BA. Development of an instrument to measure quality of nurses'work life. Graduate College of the University of Illinois at Chicago, 2001

12. Şirin M. Hemşirelik İş Yaşamı Kalitesi Ölçeği'nin Geçerlilik ve Güvenirlik Çalışması. Yüksek Lisans Tezi. Atatürk Üniversitesi Sağlık Bilimleri Enstitüsü, Erzurum, 2011.

13. Bohle P, Quinlan M, Kennedy D.et.al. Workinghours, work-life conflict and health in precarious and "permanent" employment. Rev. SaudePublica. 2004; 38: $19-25$.

14. Shevlin M, Bailey F, Adamson G. Examining the factor structure and sources of differential functioning of the Eysenck Personality Questionnaire RevisedAbbreviated. Personality and Individual Difference. 2002; 32: 479-487.

15. Ayaz S, Beydağ KD. Hemşirelerin iş yaşam kalitesini etkileyen etmenler: Balıkesir örneği. Sağllk ve Hemşirelik Yönetimi Dergisi. 2014; 1(2):60-69

16. Çatak T, Bahçecik N. Hemşirelerin iş yaşamı kalitesi ve etkileyen faktörlerin belirlenmesi. Journal of Marmara University Institute of Health Sciences. 2015; 5(2): 85-95.

17. Aslan H. Çalışanların İş Doyum Düzeylerine Göre Depresyon, Benlik Saygısı ve Denetim Odağı Algısı Değişkenlerinin İncelenmesi. Yüksek Lisans. Ankara Üniversitesi, Ankara, 2006.

18. Gibson DW. The Effect of Trust in Leader on Job Satisfaction and Intent to Leave Present Job in the Context of the Nursing Profession. PHD Thesis. University of Louisville, 2011.

19. Fung-kam L. Job satisfaction and autonomy of Hong-Kong registered nurses. Journal of Advance Nursing, 1998; 27(2): 355-363.

20. Selvi Y, Özdemir PG, Özdemir O, Aydın A, Beşiroğlu L. Sağlık çalışanlarında vardiyalı çalışma sisteminin sebep olduğu genel ruhsal belirtiler ve yaşam kalitesi üzerine etkisi. Düşünen Adam Psikiyatri ve Nörolojik Bilimler Dergisi. 2010;23: 238-243.

21. K1lıç R, Keklik B, Sağlık Çalışanlarında İș Yaşam Kalitesi ve Motivasyona Etkisi Üzerine Bir Araştırma. Afyon Kocatepe Üniversitesi İ̈FF Dergisi. 2012; 14(2): $147-160$

22. Wilson J. The impacts of shift patterns on healthcare professionals. Journal of Nursing Management. 2002; 1(1): 211- 219.

23. Demir A. Investigation of Factors Influencing Burnout Levels in the Professional and Private Lives of Nurses. International Journal of Nursing Studies. 2003; 40(8): 807-827.

24. Barrick MR, Mount MK, Judge TA. Personality and performance at the beginning of the new millenium: What we know and where do we go next? Personality and Performance, 2001; 9(1-2): 9-30. 